\title{
PRODUCTS
}

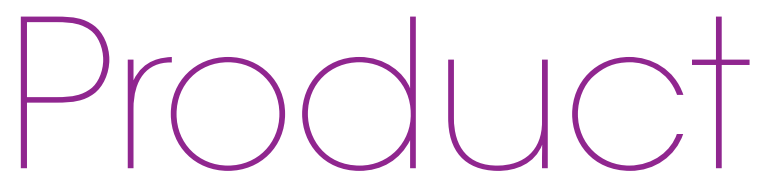

news

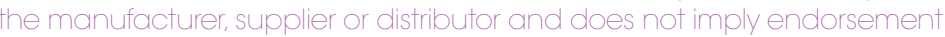

purchase or use of any product mentioned.

\section{BLACK TOOTHPASTE FOR WHITER TEETH}

\section{t.}
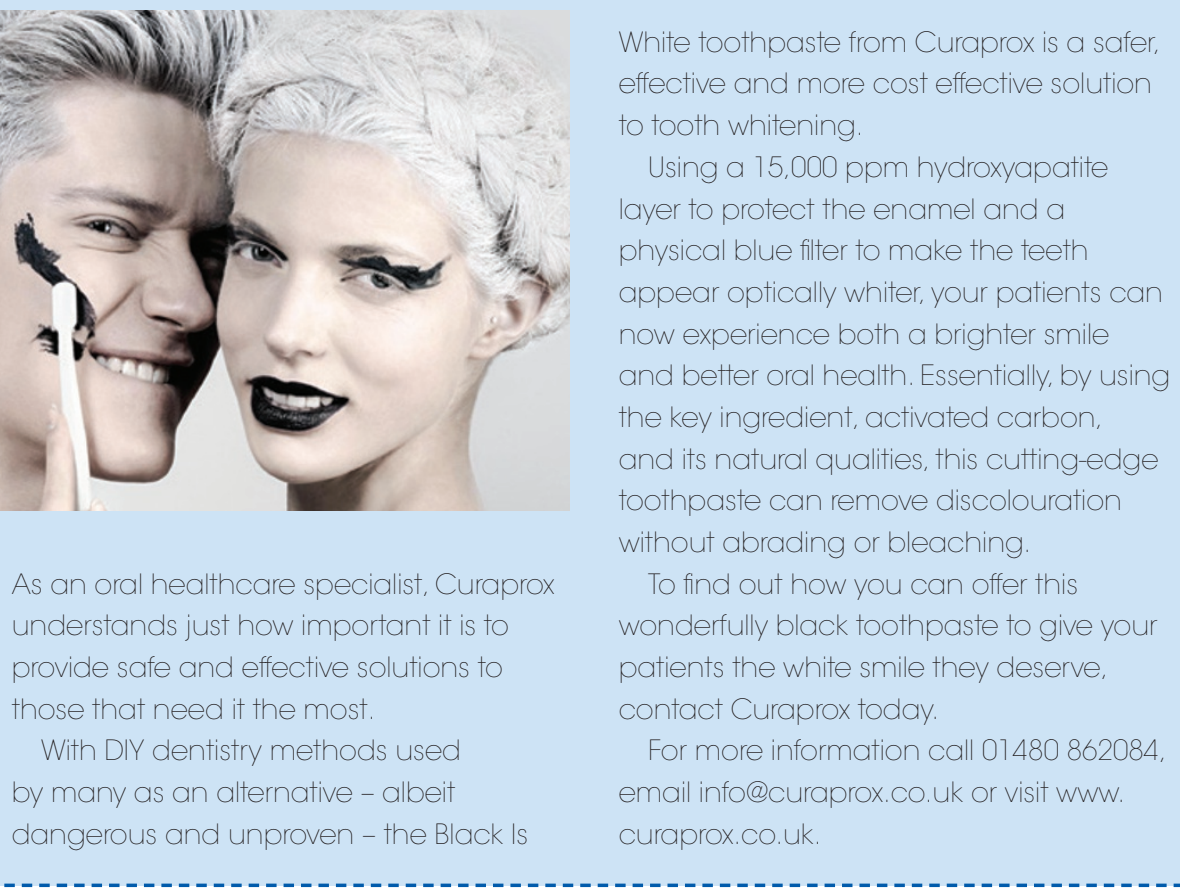

\section{SUPPRESSING THE GROWTH OF BACTERIAL FLORA}

As the Baby Boom generation reaches old age, greater numbers of people are retaining their teeth and the key issue for practitioners is controlling periodontal disease successfully.

When patients present with periodontal pockets, professional scaling and root surface debridement is of paramount importance to clear the subgingival areas of bacterial toxins

Afterwards, and to provide continued preventative treatment in pockets $>5$ $\mathrm{mm}$ deep, practitioners can also rely on PerioChip as an effective adjunctive therapy. This intra-periodontal insert contains chlorhexidine digluconate that is able to eliminate harmful bacteria for up to seven days after placement. mail info@curaprox.co.uk or visit.www.
White toothpaste from Curaprox is a safer effective and more cost effective solution to tooth whitening.

Using a 15,000 ppm hydroxyapatite layer to protect the enamel and a physical blue filter to make the teeth appear optically whiter, your patients can now experience both a brighter smile and better oral health. Essentially, by using the key ingredient, activated carbon, and its natural qualities, this cutting-edge toothpaste can remove discolouration thout abrading or bleaching. wonderfully black toothpaste to give your patients the white smile they deserve.

\section{A TOOTHPASTE YOU CAN RECOMMEND WITH CONFIDENCE}

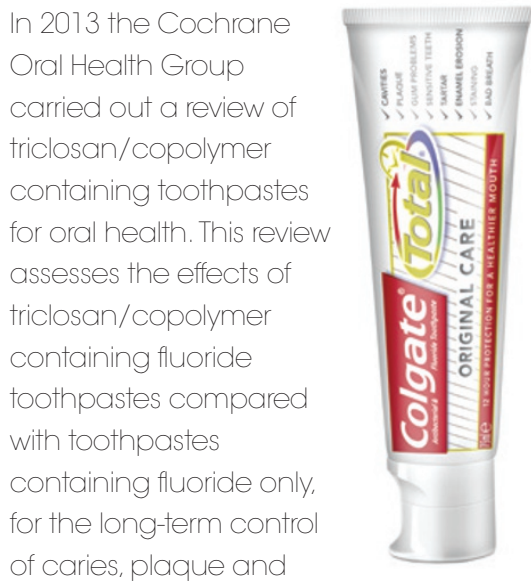

of caries, plaque and

gingivitis in children and

adults. Thirty published studies were reviewed, involving 14,835 patients who had been randomised to receive a triclosan/copolymer containing fluoride toothpaste or a fluoride toothpaste not including triclosan/copolymer

The evidence produced shows the clinical benefits of using a triclosan/ copolymer fluoride toothpaste twice daily when compared with a fluoride toothpaste (without triclosan/ copolymer). The results showed a $22 \%$ reduction in plaque, $22 \%$ reduction in gingivitis, 48\% reduction in bleeding gums, and 5\% reduction in tooth decay

This evidence led to the authors concluding 'Fluoride toothpastes containing triclosan and copolymer reduced plaque, gingival inflammation and gingival bleeding when compared to fluoride only toothpastes.

'Delivering better oral health - an evidenced based toolkit for prevention cites this systematic review in section 6 , 'Improving periodontal health' quoting the authors' findings. The toolkit also identifies Colgate Total as the only toothpaste available containing triclosan with co-polymer.

To download the Cochrane review visit www.colgateprofessional.co.uk/products/ colgate-total-toothpaste/overview.
PerioChip is also able to suppress the growth of bacterial flora in the treated site for up to 11 weeks, offering substantial ongoing therapy to assist the healing process.

Periochip is available exclusively from Dexcel Dental. To order or for further team@periochip.co.uk. information call 08000132333 or email
If you would like to promote your products or services direct to the dental industry in BDJ Team, call Andy May on 02078434785 or emaila.may@nature.com 